\title{
Improving Patient Compliance to Prophylactic Migraine Therapy
}

\author{
Michel Aubé
}

\begin{abstract}
As in many other chronic conditions, adherence to prophylactic treatment in migraine is probably poor. In chronic diseases, compliance at one year does not exceed $50 \%$. That could explain the low therapeutic gain seen with migraine preventive medications. It also renders difficult the evaluation of clinical trials on migraine prophylaxis since in most of these trials compliance is not properly assessed. From the patients' perspective, there are several factors that could explain poor adherence to recommended treatments. Essentially, these factors are the expression of the patients'subjective perception of their disease and potential remedies in a context of a positive patient-physician relationship. When migraine prophylactic treatment is considered, patients should be informed of the natural history of their disease and a diagnosis of an accelerated form of migraine should be confirmed. Prophylactic treatment at best would reduce by $50 \%$ the frequency of migraine attacks. In most studies, however, the therapeutic gain is in the order of $30-40 \%$. Treatment should be instituted for a minimum time of two to three months and if effective maintained for 6-12 months. The outcome of prophylaxis can rarely be determined in a prospective way. The choice of prophylactic regimens remains empirical, often based on the physician's experience and perception of the mechanism of migraine. A better adherence to prophylactic treatment of migraine could possibly improve outcomes but current methods of improving adherence for chronic health problems are mostly complex and not very effective.
\end{abstract}

RÉSUMÉ: Améliorer la fidélité au traitement prophylactique de la migraine. Comme il en est pour plusieurs maladies chroniques, la fidélité au traitement prophylactique de la migraine demeure probablement faible. On estime que, dans les conditions chroniques, la fidélité au traitement à un an ne dépasse pas 50\%. Ceci expliquerait peut-être le faible gain thérapeutique observé avec les agents prophylactiques courants dans la migraine. Un faible taux de fidélité au traitement rendrait aussi difficile l'interprétation des résultats des essais cliniques des agents prophylactiques puisque dans la majorité de ces essais la fidélité au traitement n'est pas mesurée d'une façon adéquate. Du point de vue du patient, plusieurs facteurs peuvent expliquer un faible taux de fidélité. Ils reflètent essentiellement la perception que développe le patient de sa maladie et de son traitement dans un contexte de relation positive avec son médecin. Avant de considérer un traitement prophylactique, le patient doit être informé de l'histoire naturelle de sa condition et un diagnostique d'une forme accélérée de migraine doit être confirmé. Au mieux, le traitement prophylactique réduira de $50 \%$ la fréquence des attaques migraineuses. Dans la plupart des études cependant, le gain thérapeutique se limite à 30 à 40\%. Pour juger de l'efficacité, le traitement doit être maintenu pour un minimum de 2 à 3 mois et, si efficace, continu pour 6 à 12 mois. Il n'existe que peu d'indices permettant de statuer d'une façon prospective sur l'efficacité d'un traitement. Le choix de l'agent prophylactique demeure empirique, basé sur l'expérience du clinicien et sur sa perception de la pathogenèse de la migraine. Une meilleure fidélité au traitement prophylactique pourrait à la rigueur en améliorer l'efficacité, mais les méthodes courantes visant à améliorer la fidélité des patients demeurent complexes et peu efficaces.

Can. J. Neurol. Sci. 2002; 29: Suppl. 2 - S40-S43

Prophylactic treatment in migraine includes changes in lifestyle, avoidance of trigger factors and, on occasion, the use of preventive medications. Such a program calls for a fairly longterm commitment from the physician and the patient. Adherence to prophylactic treatment may be the most significant challenge facing medical practice today. ${ }^{1}$ A limited number of studies have addressed the question of noncompliance in the prophylactic treatment of migraine. Since migraine is a chronic but episodic disorder, general observations on noncompliance to prophylactic treatment deriving from the study of other chronic conditions can probably be interpreted in the context of migraine prophylaxis.

\section{COMPLIANCE TO PROPHYLACTIC TREATMENT}

Overall compliance to prophylactic treatment is poor. It is estimated that only $50 \%$ of patients with chronic diseases will be compliant to their treatment at one year and that only two-thirds of the compliant group will show a strict adherence to the prescribed regimen. ${ }^{2}$ That could have significant consequences on treatment outcomes and could perhaps explain, at least in part, the relatively low therapeutic gain seen with preventive medications in migraine. Moreover, a high level of noncompliance renders difficult the interpretation of many clinical trials on prophylactic medications in migraine, since most of them do not have an adequate assessment of compliance

From the Department of Neurology and Neurosurgery, Montreal Neurological Institute, McGill University, Montréal, Québec

Reprint requests to: M. Aubé, 3801 University Street, Montréal, Québec, Canada H3A 2B4 
and since also the small number of study subjects in many of these trials further reduces the power of these trials. ${ }^{3}$ A review of studies on medication compliance ${ }^{4}$ concluded that the majority of these studies were descriptive $(64 \%)$, that only a few were multicenter, that no consistent definition of compliance was present in $41 \%$ of the research articles and that $25 \%$ of them had no validated measures of compliance.

Compliance can be assessed with patient interviews, pill counts and biological assays. Each of these methods has their limitations. Even if biological assays would seem like the most accurate method, for most of the preventive antimigraine medications they are not readily available and, if available, the potential pharmacokinetic differences between patients would render their interpretation limited. There does not seem to be any profile specific to the noncompliant patient and, in general, physicians appear to be unable to predict noncompliance. In detecting low compliance, Sackett et $\mathrm{al}^{5}$ recommend to focus on patients who are not responding to the prescribed regimen and to ask patients if "they are having trouble remembering to take all their medicine". This last question appears to be $90 \%$ specific in detecting low compliance.

\section{The PATIENT's PERSPECTIVE}

From the patient's perspective there could be multiple reasons for nonadherence to prescribed regimens. Patients are becoming more aware that a given diagnosis and recommended treatment could be wrong. They are often left without answers regarding the individual probability of treatment failure or success; the trial and error method used in the treatment of migraine is not always well understood. Patients would also consider the natural history of their condition as favourable and would prefer to maintain control of their illness. ${ }^{6}$ Furthermore, patients are much more informed of the possibility of side effects to prescribed medications. $^{7}$

Several factors influence patient compliance. They are the expression of the patient's subjective perception of the disease and of its potential remedies in a context of a co-operative and positive patient-physician relationship. See Table.

It is generally assumed that improving patient compliance

Table: Factors influencing compliance

- Willingness to accept diagnosis and recommendations

- Satisfaction with patient-physician relationship

- Patient's perception of susceptibility to disease

- The likely severity of disease if untreated

- Benefits and barriers to be derived or encountered

- Patient's preferences and expectations

- Experience with treatment regimens

- Patient knowledge

- Social interaction

- Follow-up and monitoring

Adapted from: Eraker SA, Kirscht JP, Becker MH. Understanding and improving patient compliance. Ann Intern Med 1984;100:258-268 (with permission)

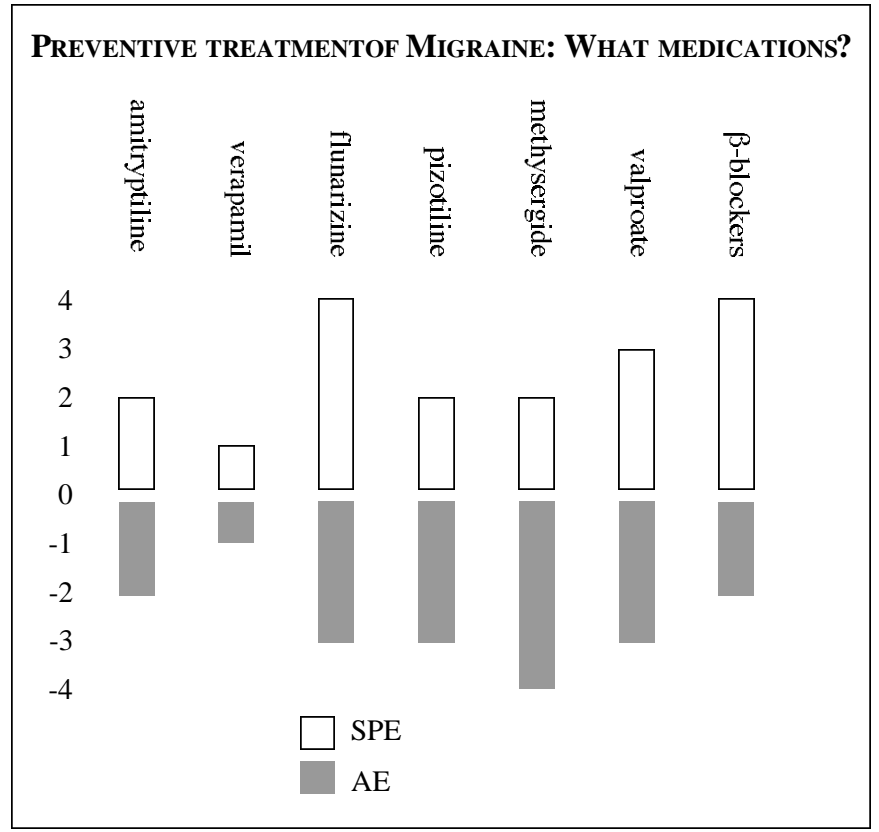

Figure: Adverse events $(A E)$ and scientific proof of efficacy for different prophylactic medications (SPE) are assessed on an empirical scale ranging from 0 to $4+$ for the best scientific proof of efficacy and from 0 to -4 for their incidence of $A E$.

Adapted from: Tfelt-Hansen P, Welch, KMA. Prioritizing prophylactic treatment of migraine. In: Olesen J, Tfelt-Hansen P, Welch KMA. (Eds.) The Headaches. 2nd edition. Lippincott Williams and Wilkins 2000:499500 (with permission).

will improve treatment outcomes in migraine prophylactic treatment; however, no specific studies to that effect are available. Noncompliance to follow-up appointments was studied in a population of chronic headache patients. ${ }^{8}$ The main reasons for noncompliance in $40 \%$ of the patients were dislike of the clinician and seeking care elsewhere. For the patients who had been compliant with their follow-up appointments, the rate of improvement was in the order of $76 \%$ and more than $85 \%$ of the patients reported a decrease in their use of analgesic or ergotamine medications.

A $40 \%$ rate of noncompliance to follow-up appointments is certainly not surprising in view of the already existing data on compliance to recommended treatments in chronic diseases. What is it that allows such a high level of noncompliance? Physician dislike needs to be spelled out more specifically. In a survey conducted by Packard, ${ }^{9}$ where physicians treating headache patients where asked about their views on patients expectations and patients were also asked about their own expectations, there was a significant discrepancy between the two groups. Both patients and physicians were asked the same 12 questions. Sixty-six percent of the physicians felt that patients were primarily expecting pain relief, whereas only $31 \%$ of the patients had the same expectations. Patients predominantly felt that explanation of the cause of their pain represented their leading need, whereas only $22 \%$ of the physicians felt the same way. Concerns about medications, explanation about 
medications, further investigations, support groups, and followups were low on the patients'preferences list.

\section{COMMUNICATING EXPECTATIONS FROM PROPHYLACTIC TREATMENT TO PATIENTS}

What can we tell our patients about their primary disease in terms of prognosis, indications and goals of prophylactic treatment and possible expectations from such a treatment?

In a study carried out by Bille ${ }^{10}$ of 73 children followed over a period of 40 years, approximately $45 \%$ became migraine-free in their adulthood life, $30 \%$ continued to have migraine on an annual basis and close to $22 \%$ experienced long intervals of freedom from migraine. These figures remained relatively stable after the age of 30 . In another study ${ }^{11}$ the yearly frequency of migraine attacks in a migraine population was found to be relatively low (less than 14 symptomatic days per year) in the majority of patients, and in less than $10 \%$ of the entire migraine population studied was the yearly frequency of migraine higher than 15 days per year (range: 15 to 180 symptomatic days per year). This last segment of the migraine population represents the target group for possible migraine prophylactic treatment. They represent $85 \%$ of the migraine patients seen in a clinic population ${ }^{12}$ and they may represent a subgroup of the general migraine population with possibly a different neurobiological profile rendering them more prone to change into a form of transformed migraine.

Since migraine is a chronic disorder which carries a favourable prognosis for most people, the goal of prophylactic therapy should be not so much to render more patients migrainefree but rather to decrease the frequency of their migraine attacks by increasing the number of patients experiencing prolonged migraine-free periods. Most studies on migraine prophylactic treatment have looked at reducing the frequency of attacks as the primary end-point. Secondary end-points such as reduction in the severity of attacks or possible prevention of transformed migraine by prophylaxis have not been widely studied.

Before considering the introduction of a migraine preventive treatment, first the diagnosis of an accelerated form of migraine should be established from a headache diary and second, an analysis of the possible trigger factors should be carried out. In some studies, ${ }^{13}$ the identification and control of some of the precipitating factors can reduce the frequency of migraine attacks by $50 \%$ at two months and this reduction is maintained through the third month of observation.

When an accelerated form of migraine is diagnosed with more than three to four severe attacks per month which are poorly-controlled with symptomatic medication, one should consider offering the patient some form of prophylactic treatment. ${ }^{14}$ The concept, however, that a possible restored response to symptomatic treatment can be re-established with prophylactic treatment has not been validated. Prophylaxis should also be considered if patients need to use symptomatic medications for more than two to three days a week. ${ }^{15}$ The empirical goal of this treatment strategy would be to prevent the possible transformation of migraine into an accelerated form with more than 15 symptomatic days per month. This concept, however, has not been validated.

What can patients with an accelerated frequency of migraine attacks expect from prophylactic treatment? In a study by Wober, ${ }^{16}$ the responders (75\%) tended to have a sustained positive effect to prophylactic treatment for approximately six months and if a second prophylactic medication was then introduced their rate of response was far less than with the first prophylactic medication used (10-25\%). With such a high incidence of nonresponders and of nonsustained response in the responders, one may ask the question about the possible indication for an earlier use of prophylactic treatment in the course of migraine. In that study, patients who were found to be nonresponders had a high frequency of attacks at base-line, a previous history of medication-induced headaches or a previous history of exposure to multiple prophylactic medications.

In general, physicians do not have much in the way of indices to help them predict specifically the outcome of any prophylactic medication in a given patient. Their recommended treatment is most often based on the trial and error method minimising the potential adverse events with slow introduction of the medications at low dosages. Only a very limited number of studies have been aimed at finding a specific patient profile that would be more responsive to a specific prophylactic medication. Lucetti ${ }^{17}$ found that flunarizine responders had a low frequency of migraine attacks with a positive family history whereas at base line nonresponders had a high frequency of attacks and a history of medication overuse. With divalproex sodium there was a correlation between the rate of improvement and the frequency of attacks at base-line.

In addition to being a trial and error exercise, the choice of the prophylactic medications is also often based on the physician's experience with a given drug and perhaps on his concept of headache pathogenesis. Indeed, if cortical hyperexcitability with enhanced sensory systems appear as a predominant phenomenon in a patient, beta-blockers with their proven normalising effect on cortical hyperexcitability ${ }^{18}$ or valproate might be the drugs to consider. If an element of sleep disturbance, stress or low pain threshold is suspected as one of the possible leading contributing factors, a tricyclic analgesic could be considered. Calcium channel blockers could be considered for their blocking effect on the release of nitric oxide, a substance possibly responsible for the early activation of migraine pain. ${ }^{19}$ None of the antimigraine prophylactic medications, however, appears to be specific to any one of the possible neurobiological systems disrupted at the time of a migraine attack. Beta-blockers, valproate and flunarizine can probably be considered as the drugs with the best potential for improvement but flunarizine and valproate carry a significant risk of adverse events ${ }^{20}$ (Figure).

Since prophylactic medications rarely work in the first month of treatment, they should be used for a minimum of three months at which time in most clinical studies the optimum effect is observed. ${ }^{21} \mathrm{~A}$ very good response to migraine prophylaxis is considered present if there is a 50\% reduction in the frequency of the attacks at three months. ${ }^{22}$ If a positive effect is obtained from migraine prophylaxis at three months, the treatment should be maintained for a period of 6-12 months before considering discontinuing the medication. Only approximately $25 \%$ of patients on prophylaxis will show long-term improvement. ${ }^{16}$

If monotherapy has failed, is there a place for combination preventive therapy? No data exist on the efficacy of combined prophylactics in the prevention of migraine. Many clinicians 
would elect to use small doses of more than one prophylactic medication, particularly if there are associated conditions such as sleep disorders or tension states. In migraine, no one single pathogenic mechanism has been implicated and several mechanisms are likely.

\section{CONCLUSION}

In final analysis, the use of prophylaxis in migraine would provide, at least on a temporary basis, a therapeutic gain of 30$40 \% .{ }^{23}$ Most clinical studies used as references in clinical practice rarely extend beyond a study period of three to six months. The patients eligible for prophylaxis may represent a subgroup of migraineurs with a possibly different neurobiology through kindling or transformation in their central nociceptive systems.

In order to improve compliance to migraine prophylaxis, patients should be reassured about their diagnosis and informed about the possible treatment options. Their specific needs and preferences should be taken into consideration and they should be provided with adequate follow-up. However, "current methods of improving adherence for chronic health problems are mostly complex and not very effective". ${ }^{24}$

\section{ACKNOWLEDGEMENT}

The current paper derives in part from the content of a presentation given at a symposium held in Toronto in February 2001 and for which the author received an honorarium from GlaxoWellcome Inc.

\section{REFERENCES}

1. Haynes RB. Introduction. In: Haynes RB, Taylor DW, Sackett DL, (eds). Compliance in Health Care. Baltimore: Johns Hopkins University Press 1979;1-7.

2. Eraker SA, Kirscht JP, Becker MH. Understanding and improving patient compliance. Ann Intern Med 1984;100:258-268.

3. Feinstein AR. 'Compliance bias' and the interpretation of therapeutic trials. In: Haynes RB, Taylor DW, Sackett DL, (eds). Compliance in Health Care Baltimore: Johns Hopkins University Press; 1979:309-322.

4. Nichol MB, Venturini F, Sung JC. A critical evaluation of the methodology of literature on medication compliance. Ann Pharmacother 1999;33(5):531-540.

5. Sackett DL, Richardson WS, Rosenberg W, Haynes RB, (eds).
Evidence-based Medicine: How to Practice and Teach EBM. Churchill Livingstone 1998;175-178.

6. Jones I, Britten N. Why do some patients not cash their prescription? Br J Gen Pract 1998;48(426):903-905.

7. Martys CR. Adverse reactions to drugs in general practice. Br Med J 1979;2:1194-1197.

8. Spierings EL, Miree LF. Noncompliance with follow-up and improvement after treatment at a headache center. Headache 1993;33(4):205-209.

9. Packard RC. What does the headache patient want? Headache 1979;19:370-374.

10. Bille B. A 40-year follow-up of school children with migraine. Cephalalgia 1997;17:488-491.

11. Rasmussen BK, Olesen J. Migraine with aura and migraine without aura: an epidemiological study. Cephalalgia 1992;12:221-228.

12. Zagami AS, Rasmussen BK. Symptomatology of migraine without aura. In: Olesen J, Tfelt-Hansen P, Welch KMA. (Eds). The Headaches. 2nd ed. Lippincott Williams and Wilkins 2000:337343.

13. Blau JN, Thavapalan M. Preventing migraine: a study of precipitating factors. Headache 1988;28:481-483.

14. Pryse-Phillips WEM, Dodick DW, Edmeads JG, et al. Guidelines for the diagnosis and management of migraine in clinical practice. Can Med Assoc J 1997;156:1273-1287.

15. Silberstein SD. Preventive treatment of migraine: an overview. Cephalalgia 1997; 17:67-72.

16. Wober C, Wober B, Koch G, Wessely P. Long-term results of migraine prophylaxis with flunarizine and beta-blockers. Cephalalgia 1991;11:251-256.

17. Lucetti C, Nuti A, Pavese $\mathrm{N}$, et al. Flunarizine in migraine prophylaxis: predictive factors of a positive response. Cephalalgia 1998;18:349-352.

18. Schoenen J, Martens de Noordhout A, Timsit-Berthier M, Timsit M. Contigent negative variation and efficacy of beta-blocking agents in migraine. Cephalalgia 1986;6:229-233.

19. Ayajiki K, Okamura T, Toda N. Flunarizine, an antimigraine agent, impairs nitroxidergic nerve function in cerebral arteries. Eur $\mathbf{J}$ Pharmacol 1997;329:49-53.

20. Tfelt-Hansen P, Welch KMA. Prioritizing prophylactic treatment of migraine. In: Olesen J, Tfelt-Hansen P, Welch KMA. (Eds). The Headaches. 2nd ed. Lippincott Williams and Wilkins 2000:499500 .

21. Davidoff RA. Migraine: Manifestations, Pathogenesis, and Management. Philadelphia: FA Davis Co. 1995.

22. Silberstein SD. Preventive treatment of migraine: an overview. Cephalalgia 1997; 17:67-72.

23. Ferrari MD. Migraine. Lancet 1998;351:1043-1051.

24. Haynes RB, Montague P, Oliver T, et al. Interventions for helping patients to follow prescriptions for medications. Cochrane Database Syst Rev 2000;(2):CD000011. 